\title{
The Effectiveness of Nitrous Oxide Sedation Combined with Behavior Management in a Private Dental Practice in Saudi Arabia
}

\author{
Najwa Mansour Joharji* \\ Consultant Pediatric Dentist, Pediatric Dental Consulting Center Riyadh, Saudi Arabia
}

*Corresponding author: Najwa Mansour Joharji, Consultant Pediatric Dentist, Pediatric Dental Consulting Center Riyadh, Saudi Arabia

\begin{abstract}
Purpose: To show the different dental treatment responses and outcomes of different pediatric age groups under nitrous oxide $\left(\mathrm{N}_{2} \mathrm{O}\right)$, based on the experiences of a private practice, to show that $\mathrm{N}_{2} \mathrm{O}$ inhalation is an effective tool for all young patients if used in conjunction with behavior management techniques, and to show that $\mathrm{N}_{2} \mathrm{O}$ is an outstanding tool for decreasing the dentist risk and stress when using pre-medication or general anesthesia.

Methods: A total of 826 middle- and upper-class children 394 males and 432 females, ranging in age from $<2$ to 13 years old, participated in this study using the rapid induction method. All patients were treated over a total of 1,924 appointments (average, 2-3 visits per patient). The PDCC (Pediatric Dental Consulting Center) created criteria for each child's evaluation at the first visit prior to categorization, according to which behavioral rating scale he or she belonged. Moreover, these categorizations were based on McDonald and Frankel's Behavior Rating Scale with Wright's Modification, in conjunction with the PDCC criteria. During the first visit, we enhanced the parents-child-dentist relationship. The child was familiarized with the dental environment by a skillful dental team, while the parents were educated about several behavior management techniques and the use of $\mathrm{N}_{2} \mathrm{O}$ sedation.

Results: $\mathrm{N}_{2} \mathrm{O}$ worked effectively when combined with basic behavior management techniques. The child's first visit to the dental clinic should only include familiarization, acclimatization and enhancement of the parent-child-dentist relationship, as well as education. It was observed that, patients 4-6 years old responded best including children with bad experience and different personalities.

Conclusion: Behavior management and $\mathrm{N}_{2} \mathrm{O}$ constitute an excellent combination. If both applied and used properly, pediatric patients can be treated successfully. The pediatric dentist should master his or her communication skills with children and parents. Based on this study, children with moderate to severe anxiety can be managed with proper application of behavior management and with the use of $\mathrm{N}_{2} \mathrm{O}$ sedation (with a high success rate of $91 \%$ ).
\end{abstract}

Keywords: Nitrous oxide; behavior management; $\mathrm{N}_{2} \mathrm{O}$ sedation

Abbreviations: BBG: Basic Behavior Guidance; BG: Behavior Guidance; CNS: Central Nervous System; DFA: Dental Fear and Anxiety; DBP: Dental Behavioral Problem; CDA: Child Dental Anxiety

\section{Introduction}

Basic behavior guidance (BBG) is based on scientific principles. The proper implementation of behavior guidance $(B G)$ requires an understanding of these principles. BG is more than pure science, and it requires skill, empathy, coaching and listening [1]. Thus, BG is a clinical art form that is built on a foundation of science. Moreover, today's treatment of children provides a foundation for that child's future acceptance of dental treatment. We always have goals when working with children. The first goal is by far the most important: the child should be willing to return to the office or clinic for subsequent visits [2]. The second goal is the completion of the dental procedure. Lack of child cooperation is primarily a result of fear and discomfort [2]. Nitrous oxide $\left(\mathrm{N}_{2} \mathrm{O}\right)$ inhalation sedation should be offered to children with mild to moderate anxiety to enable them to accept dental treatment more readily and 
to facilitate their coping in future visits. This sedation should not be segregated from the support provided to the child by the dentist [3]. In many parts of the world where deep sedation techniques are more common, the use of such agents is often limited to hospitals. $\mathrm{N}_{2} \mathrm{O}$ inhalation sedation remains the preferred technique for the pharmacological management of anxious pediatric dental patients [3]. Dentists have expertise controlling anxiety and pain for their patients. Anxiety and pain can be modified by psychological techniques, but in many situations, pharmacological interventions are needed [4]. $\mathrm{N}_{2} \mathrm{O}$ is a colorless and odorless gas, with a faint, sweet smell. It is an effective analgesic/anxiolytic agent (a drug that relieves anxiety), which causes central nervous system (CNS) depression and euphoria and has little effect on the respiratory system. $\mathrm{N}_{2} \mathrm{O}$ is rapidly absorbed, allowing for both rapid onset and recovery (2-3 minutes) [4]. There are no absolute contraindications for the administration of $\mathrm{N}_{2} \mathrm{O}$-oxygen inhalation, only relative ones. The most common contraindication is the patient's inability to perform nasal respiration because of obstruction from a cold, a deviated septum or enlarged adenoids [4]. The most common undesirable effects of $\mathrm{N}_{2} \mathrm{O}$ are nausea and vomiting, which rarely occur and are primarily observed only when the concentration reaches or exceeds 50\% [5]. Behavior management is important for facilitating good-quality dental treatment in pediatric patients.

\section{Methods}

A total of 826 patients (age range, younger than 2 years of age to 13 years old) were randomly selected from middle- and upper-class children at the Pediatric Dental Consulting Center (PDCC) in Riyadh, the capital of Saudi Arabia. The study was performed by a female pediatric dentist practitioner based on 6 years of studying patients treated under $\mathrm{N}_{2} \mathrm{O}$ sedation between 2000 and 2005 over a total of 1,924 appointments. A rapid induction method was used in young children at a concentration of $70 \% \mathrm{~N}_{2} \mathrm{O}$, which was incrementally decreased, while the other children received mostly 40-50\% $\mathrm{N}_{2} \mathrm{O}$. After the treatment, the patient was under $100 \%$ oxygen for $3-5$ minutes using nasal hood with scavenging circuit (Accutron Inc., Parkside Lane, Phoenix, AZ 85027, USA). The patients' responses to $\mathrm{N}_{2} \mathrm{O}$ sedation were evaluated from their first visit to the clinic for treatment until the last visit, when the treatment was either completed or partially completed. The PDCC created for each child's evaluation at the first visit prior to categorization, according to which behavioral rating scale he or she belonged. Each child was categorized after a tell-show-do technique and examination. As a strict rule, the dentist never attempted to start any dental work during the first visit. The parental separation technique was applied for all patients during the dental treatments, except with children younger than 3.5 years old, for whom the parents were allowed to remain inside the dental operating room if needed. The parents were allowed to look inside the room once during treatment to allow their children to feel relaxed. Audio music was also used as a distraction tool and to reduce anxiety [6-12]. Moreover, these categorizations were based on McDonald and Frankel's Behavior Rating Scale with Wright's Modification, in conjunction with the PDCC criteria listed below for testing and comparison.

\section{Naj Criteria for Patient Selection at the First Visit}
a) New Experience (with or without gag reflex)
b) Bad Experience
c) Young Age (younger than 31/2 years old)
d) Child's Personality (spoiled, temper tantrums, defiant, high strung, fearful, compulsive, suspicious, tense)

e) Special Needs

\section{Naj Behavioral Rating Scale Modifications}

a) Cooperative (++): These children had good rapport, were interested in the dental procedures, and laughed and enjoyed themselves.

b) Potentially Cooperative (+): These children accepted treatment but were perhaps cautious or reserved, with minimal apprehension, and they followed directions.

c) Uncooperative (-): These children were reluctant and uncooperative, with limited negativity, sullenness, and withdrawal.

d) Definitely Uncooperative (- -): These children refused treatment, with forceful crying, fear and extreme negativity.

During the first visit, we enhanced the parents-childdentist relationship. The child was familiarized with the dental environment by a skillful dental team, while the parents were educated about several behavior management techniques and the use of $\mathrm{N}_{2} \mathrm{O}$ sedation. A well-implemented policy for the parent separation method was discussed thoroughly for the benefit of the child. In patients with special needs and younger patients, the use of protective stabilization was explained to the parents. For children who were definitely uncooperative upon categorization, we informed the parents regarding the possible use of HOME. A written parental consent was acquired. Subsequently, applying behavior management guidance (BMG) with the child, he or she was psychologically prepared for the next visit by choosing and smelling the $\mathrm{N}_{2} \mathrm{O}$-scented mask (Accutron Inc., Single-Use Nasal Hoods), which made the child excited to return and start the treatment at the second visit; the first visit ended with positive reinforcement (toys).

\section{Results}

A total of 826 patients were enrolled in this study; the children ranged in age from younger than 2 years of age to 13 years old and were treated at PDCC under nitrous oxide sedation from 2000 to 2005 over 1,924 visits. The minimum time per session was 
approximately 45 minutes, while the average number of visits for each patient was 2-3 appointments. The study included 394 (48\%) male patients and 432 (52\%) female patients. The patients were classified after health and demographic information was gathered at the first appointment. In 6 years of studying patient $(n=826)$ responses to $\mathrm{N}_{2} \mathrm{O}, 709$ (86\%) patients demonstrated positive responses, and 117 (14\%) had negative responses. The results also indicated that among the patients selected for this study, $76 \%$ (627) completed their treatments, and 24\% (199) were unable to complete their treatments (Table 1). The number of patients who responded negatively or positively were recorded based on the selection criteria. The results classified 259 patients as New Experiences, 184 as Bad Experiences, 137 as Young Age, 235 as Child's Personality, and 11 as Special Needs (Table 2). Among the evaluated patients, $86 \%$ (709) responded positively to treatments under $\mathrm{N}_{2} \mathrm{O}$; the highest positive response rate was for the children who were classified as New Experiences (94\%), while for those classified as bad experiences, the rate was $91 \%$. Child's Personality was the third highest classification, with $86 \%$, while Young Age $(66 \%)$ and Special Needs (64\%) had the lowest positive responses among all groups.

Table 1: Total Number of Patients and Rates of Each Age Group, Gender and Positive and Negative Response, Completed/Incomplete the Treatments under Nitrous Oxide Sedation.

\begin{tabular}{|c|c|c|c|c|c|c|c|}
\hline \multirow{2}{*}{ Age Group } & \multirow{2}{*}{ Pt No. } & \multicolumn{2}{|c|}{ Gender } & \multicolumn{2}{|c|}{ Response } & \multicolumn{2}{|c|}{ Treatment } \\
\hline & & Male & Female & Positive & Negative & Complete & Incomplete \\
\hline Below 2 to $<3$ & 46 & \multirow{7}{*}{394} & \multirow{7}{*}{432} & \multirow{7}{*}{709} & \multirow{7}{*}{117} & \multirow{7}{*}{627} & \multirow{7}{*}{199} \\
\hline 3 to $<4$ & 133 & & & & & & \\
\hline 4 to $<5$ & 161 & & & & & & \\
\hline 5 to $<6$ & 165 & & & & & & \\
\hline 6 to $<7$ & 118 & & & & & & \\
\hline 7 to $<8$ & 85 & & & & & & \\
\hline 8 to 13 & 118 & & & & & & \\
\hline Total / Ratio & 826 & $48 \%$ & $52 \%$ & $86 \%$ & $14 \%$ & $76 \%$ & $24 \%$ \\
\hline
\end{tabular}

Table 2: Total Number of Patients and Rates of Each Age Group, Gender and Positive and Negative Response, Completed/Incomplete the Treatments under Nitrous Oxide Sedation.

\begin{tabular}{|c|c|c|c|c|c|c|}
\hline \multirow{3}{*}{$\begin{array}{l}\text { Criteria of Patient } \\
\text { Selection }\end{array}$} & \multicolumn{4}{|c|}{ Response to Treatment under Nitrous Oxide } & \multirow{2}{*}{\multicolumn{2}{|c|}{ Total }} \\
\hline & \multicolumn{2}{|c|}{ Positive } & \multicolumn{2}{|c|}{ Negative } & & \\
\hline & No. & Rate & No. & Rate & No. & Rate \\
\hline New Experience & 243 & $94 \%$ & 16 & $6 \%$ & 259 & $31 \%$ \\
\hline Bad Experience & 168 & $91 \%$ & 16 & $9 \%$ & 184 & $22 \%$ \\
\hline Child Personality & 201 & $86 \%$ & 34 & $14 \%$ & 235 & $28 \%$ \\
\hline Young Age & 90 & $66 \%$ & 47 & $34 \%$ & 137 & $17 \%$ \\
\hline Special Needs & 7 & $64 \%$ & 4 & $36 \%$ & 11 & $1 \%$ \\
\hline Total & 709 & $86 \%$ & 117 & $14 \%$ & 826 & 100 \\
\hline
\end{tabular}

Negative response to treatment under $\mathrm{N}_{2} \mathrm{O}$ was also evaluated, indicating an overall significantly low rate $(14 \%)$ of 117 patients. The results also showed that the special needs and young age patients had the highest negative response rates to treatments under $\mathrm{N}_{2} \mathrm{O}, 36 \%$ and $34 \%$, respectively, while child personality had the lowest negative response (14\%). Bad experiences and new experiences showed the lowest negative responses to treatments under $\mathrm{N}_{2} \mathrm{O}, 9 \%$ and $6 \%$, respectively. The patient behavior scale was also evaluated to determine its effects on the children treated under $\mathrm{N}_{2} \mathrm{O}$. The results for all patient groups were classified using the PDCC Behavioral Rating Scale. The data showed that 251 (30\%) patients were classified as Potentially Cooperative, 379 were classified as (46\%) Uncooperative, and 196 (24\%) were classified as Definitely Uncooperative, while no patients were classified as cooperative
(Table 3). The 826 patients treated under $\mathrm{N}_{2} \mathrm{O}$ had 1,924 visits, with a minimum time per session of approximately 45 minutes. The average treatment time per patient was 2 to 3 appointments. After the evaluation was conducted, each patient was classified using the PDCC Behavioral Rating Scale (Table 3).The results showed that the highest positive response rate to treatment under $\mathrm{N}_{2} \mathrm{O}$, was in the Potentially Cooperative patients (93\%), followed by those Uncooperative(90\%), while the Definitely Uncooperative group showed a lower positive response (68\%). The negative response rate to treatment under $\mathrm{N}_{2} \mathrm{O}$, which was evaluated using the PDCC Behavioral Rating Scale, showed that the highest negative response rate was in the Definitely Uncooperative patients (32\%), with the Uncooperative and Potentially Cooperative groups showed lower negative response rates of $10 \%$ and $7 \%$, respectively. 
Table 3: Number and Rate (\%) of the Patients Positive and Negative Response, treated under Nitrous Oxide Sedation, Grouped According to Patient Behavioral Rating Scale.

\begin{tabular}{|c|c|c|c|c|c|c|}
\hline \multirow{2}{*}{$\begin{array}{c}\text { Behavioral Rating } \\
\text { Scale }\end{array}$} & \multicolumn{3}{|c|}{ Response to Treatment under Nitrous Oxide } & \multicolumn{3}{c|}{ Total } \\
\cline { 2 - 7 } & No. & Rate & No. & Rate & No. & Rate \\
\hline Cooperative (++) & 0 & 0 & 0 & 0 & 0 & 0 \\
\hline $\begin{array}{c}\text { Potentially } \\
\text { Cooperative (+) }\end{array}$ & 234 & $93 \%$ & 17 & $7 \%$ & 251 & $30 \%$ \\
\hline Uncooperative (-) & 341 & $90 \%$ & 38 & $10 \%$ & 379 & $46 \%$ \\
\hline $\begin{array}{c}\text { Definitely } \\
\text { Cooperative (--) }\end{array}$ & 134 & $68 \%$ & 62 & $32 \%$ & 196 & $24 \%$ \\
\hline Total & 709 & $86 \%$ & 117 & $14 \%$ & 826 & 100 \\
\hline
\end{tabular}

Regarding treatment status, and the results showed that among the 627 (76\%) patients who completed treatments under $\mathrm{N}_{2} \mathrm{O}, 555$ patients completed treatment with positive responses (using the PDCC Behavior Rating Scale), and 72 patients completed treatment with negative responses. An incomplete status was reported for 199 (24\%) patients, with 85 patients stopping treatments at the parents' request and 69 patients failing to complete treatment because they did not appear at their appointments (NSU) (Table 4). All 826 patients were also divided by age group to evaluate which group had the most positive response. There were total of 46 patients that were between $<2$ and $<3$ years, 133 patients between 3 and $<4,161$ patients between 4 and $<5,165$ patients between 5 and $<6,118$ patients between 6 and $<7,85$ patients between 7 and
$<8$, and 118 patients between 8 and 13 years of age. The results indicated that the patients with positive response were found in all age groups older than 3 years old, with the success rate ranging between $86 \%$ and $95 \%$. However, the 6 to $<7$-year-old age group showed the highest success rate (95\%), while 2 year to $<3$-yearold age group showed the lowest positive response rate $(57 \%)$ and, similarly, the highest rate of negative response. Patients 3 to $>4$ years of age showed a positive response rate $(74 \%)$ under $\mathrm{N}_{2} \mathrm{O}$ (Table 5). Sex was also evaluated to test its effect on the patients' responses to treatment under $\mathrm{N}_{2} \mathrm{O}$. There were 394 (48\%) male patients and 432 (52\%) female patients. The results showed that girls tended to respond more positively to treatment (54\%) than boys (46\%) (Table 6).

Table 4: Number and Rate (\%) of the Positive and Negative Respond Patients Completed or Stopped Treatments under Nitrous Oxide Sedation, Grouped According to Patient Treatment Status.

\begin{tabular}{|c|c|c|c|c|c|c|}
\hline \multirow{3}{*}{$\begin{array}{l}\text { Behavioral Rating } \\
\text { Scale }\end{array}$} & \multicolumn{4}{|c|}{ Response to Treatment under Nitrous Oxide } & \multirow{2}{*}{\multicolumn{2}{|c|}{ Total }} \\
\hline & \multicolumn{2}{|c|}{ Positive } & \multicolumn{2}{|c|}{ Negative } & & \\
\hline & No. & Rate & No. & Rate & No. & Rate \\
\hline Completed & 555 & $89 \%$ & 72 & $11 \%$ & 627 & $76 \%$ \\
\hline $\begin{array}{l}\text { Incomplete (Pt } \\
\text { Request*) }\end{array}$ & 85 & $80 \%$ & 21 & $20 \%$ & 106 & $13 \%$ \\
\hline $\begin{array}{c}\text { Incomplete (Pt } \\
\left.\text { NSU }^{* *}\right)\end{array}$ & 69 & $74 \%$ & 24 & $26 \%$ & 93 & $11 \%$ \\
\hline
\end{tabular}

* Patient stopped the treatment by parent's request

** Patients did not show up to finish the treatments.

Table 5: Number and Rate (\%) of the Patients (Positive and Negative Response), Treated under Nitrous Oxide Sedation, Grouped According to Age.

\begin{tabular}{|c|c|c|c|c|c|c|}
\hline \multirow{2}{*}{ Age Group } & \multicolumn{3}{|c|}{ Response to Treatment under Nitrous Oxide } & \multicolumn{2}{c|}{ Total } \\
\cline { 2 - 7 } & No. & Rate & No. & Rate & No. & Rate \\
\cline { 2 - 7 } & 26 & $57 \%$ & 20 & $43 \%$ & 46 & $6 \%$ \\
\hline Below 2 to $<3$ & 98 & $74 \%$ & 35 & $26 \%$ & 133 & $16 \%$ \\
\hline 3 to $<4$ & 147 & $91 \%$ & 14 & $9 \%$ & 161 & $19 \%$ \\
\hline 4 to $<5$ & 146 & $88 \%$ & 19 & $5 \%$ & 165 & $20 \%$ \\
\hline 5 to $<6$ & 112 & $95 \%$ & 6 & & 118 & $14 \%$ \\
\hline 6 to $<7$ & & & & & & \\
\hline
\end{tabular}




\begin{tabular}{|c|c|c|c|c|c|c|}
\hline 7 to $<8$ & 73 & $86 \%$ & 12 & $14 \%$ & 85 & $10 \%$ \\
\hline 8 to 13 & 107 & $91 \%$ & 11 & $9 \%$ & 118 & $14 \%$ \\
\hline Total / Ratio & 709 & $86 \%$ & 117 & $14 \%$ & 826 & 100 \\
\hline
\end{tabular}

Table 6: Number and Rate (\%) of the Patient's (Positive and Negative Response), Treated under Nitrous Oxide Sedation, Grouped According to Patient Gender.

\begin{tabular}{|c|c|c|c|c|c|c|}
\hline \multirow{3}{*}{ Gender } & \multicolumn{4}{|c|}{ Response to Treatment under Nitrous Oxide } & \multirow{2}{*}{\multicolumn{2}{|c|}{ Total }} \\
\hline & \multicolumn{2}{|c|}{ Positive } & \multicolumn{2}{|c|}{ Negative } & & \\
\hline & No. & Rate & No. & Rate & No. & Rate \\
\hline Male & 327 & $46 \%$ & 67 & $57 \%$ & 394 & $48 \%$ \\
\hline Female & 382 & $54 \%$ & 50 & $43 \%$ & 432 & $52 \%$ \\
\hline Total & 709 & $86 \%$ & 117 & $14 \%$ & 826 & 100 \\
\hline
\end{tabular}

Among the patients, 145 completed treatment under $\mathrm{N}_{2} \mathrm{O}$ combined with another means of control, including a Papoose board (PB), voice control and hand-over-mouth (HOME). Voice Control and HOME were applied in 33 and 7 patients, respectively. In 826 patients, the low rate of HOME indicated that this technique was seldom used (only as a last resort). A total of 105 patients 3.1 years old and younger were treated under $\mathrm{N}_{2} \mathrm{O}$ using a PB. These patients responded positively with this behavioral management technique (Table 7). There were 117 (14\%) patients who exhibited negative behavior during $\mathrm{N}_{2} \mathrm{O}$ treatment, and they were treated

Table 7: Number and Rate (\%) of Patients Treated under Nitrous Oxide Sedation Combined with Other Means of Control Managements Distribution.

\begin{tabular}{|c|c|c|c|c|}
\hline \multirow{2}{*}{ Years } & Voice Control & Home* & Papoose Board ${ }^{* *}$ & No. \\
\cline { 2 - 5 } & No. & No. & 16 & 30 \\
\hline $1^{\text {st }}$ Year & 12 & 2 & 12 & 16 \\
\hline $2^{\text {nd }}$ Year & 3 & 1 & 8 & 9 \\
\hline $3^{\text {rd }}$ Year & 1 & 1 & 18 & 22 \\
\hline $4^{\text {th }}$ Year & 3 & 2 & 32 & 27 \\
\hline $5^{\text {th }}$ Year & 6 & 1 & 105 & 41 \\
\hline $6^{\text {th }}$ Year & 8 & 7 & & 145 \\
\hline Total & 33 & & & 2 \\
\hline
\end{tabular}

* Hand Over Mouth Exercise (HOME)

** Use on age 3.1 years and below.

Table 8: Number and Rate (\%) of Negative Response Patients Nitrous Oxide Sedation to the Solution of Both Completed and Incomplete Treatments Using Other Sedation Technique or Solution and Management.

\begin{tabular}{|c|c|c|c|c|c|c|}
\hline \multirow{3}{*}{ Solution \& Management } & \multicolumn{4}{|c|}{ Treatment of the Negative Responded Patient under Nitrous Oxide } & \multirow{2}{*}{\multicolumn{2}{|c|}{ Total }} \\
\hline & \multicolumn{2}{|c|}{ Completed } & \multicolumn{2}{|c|}{ Incomplete } & & \\
\hline & No. & Rate & No. & Rate & No. & Rate \\
\hline Nasal Sedation & 28 & $82 \%$ & 6 & $18 \%$ & 34 & $29 \%$ \\
\hline Oral Seduction & 1 & $25 \%$ & 3 & $75 \%$ & 4 & $3 \%$ \\
\hline GA & 2 & $40 \%$ & 3 & $60 \%$ & 5 & $4 \%$ \\
\hline By force (Negative Behavior) & 41 & $55 \%$ & 33 & $45 \%$ & 74 & $63 \%$ \\
\hline Total & 72 & $62 \%$ & 45 & $38 \%$ & 117 & 100 \\
\hline
\end{tabular}




\section{Discussion}

Behavior management and $\mathrm{N}_{2} \mathrm{O}$ work best when the treating dentist has full knowledge of how to combine them. According to the above-mentioned results, a proper and correct approach during a child's first visit to the dental clinic is important in shaping the child's attitude toward dental treatment. BG is a continuum of interaction involving the dentist, dental team, patient and parents and is directed towards communication and education. Therefore, BG is as much an art as a science. It is not an application of individual techniques created to "deal" with children but instead, it is a comprehensive, continuous method meant to develop and nurture the relationship between the patient and doctor, ultimately building trust and allaying fear and anxiety [1,13]. Successful behavior management enables the dental practitioner to perform treatments safely and efficiently and to promote a positive dental attitude in the child [1]. E Bajic S. et al. made a review about child psychological, cognitive, physiological and other kinds of development. Also, the reason for dental fear and anxiety (DFA) and dental behavioral problem (DBP) were analysed and how the child patient could cope up with them [13]. In this study, the patients who presented as new experiences ( $1^{\text {st }}$ timers) definitely had a high positive response rate under $\mathrm{N}_{2} \mathrm{O}$ sedation, as shown in this study (94\%), provided the dentist followed the step-by-step clinical guidelines on behavior management regarding how to manage these children from the start. The reasons for non-compliance in the healthy, communicating child are often more subtle and difficult to diagnose. Major factors contributing to poor cooperation can include fears transmitted from parents, previous unpleasant dental or medical experiences, inadequate preparation for the first encounter in the dental environment, or dysfunctional parenting practices [1]. Children with negative dental experiences are the result of improper approaches by unskilled dentists. Based on this study, children with previous negative experience responded positively, with a high rate of $91 \%$. Their attitudes toward dental treatment could still be reversed using a psychological approach and behavior management to reduce their fears and anxieties and to convince them to undergo treatment. The family background and parents' disciplinary strategy play roles in shaping a child's personality, which is the outcome of pre-dispositions to certain behaviors paired with the remarkably strong effects of the social and family environments $[14,15]$. These children possess behavioral problems that can be altered. Unfortunately, various barriers can hinder the achievement of successful outcomes. Developmental delay, physical/mental disability, and acute or chronic disease are all potential reasons for non-compliance [1].

Reasons were well documented in this study, in which young age and special needs patients had non-compliance rates of $66 \%$ and $64 \%$, respectively. Young children and children with physical/ mental disabilities are expected to have high negative response rates because of their low levels of understanding. Furthermore, the $\mathrm{BG}$ approach is limited in this group, but we could nevertheless apply some of the basic techniques. Using $\mathrm{N}_{2} \mathrm{O}$ and protective stabilization (the PB), cooperation could be established. In this study, written consent for using protective stabilization was provided by the parents after extensive explanations. We agreed with previous studies that demonstrated parental acceptance of the PB depends on a positive explanation of the technique $[16,17]$. The use of the PB should be explained to the parents at the first planning visit and not during treatment. The dentist requires the full cooperation of the child to provide quality treatment. In this study, the positive response was high, indicating that by combining basic behavior management with protective stabilization and $\mathrm{N}_{2} \mathrm{O}$ sedation, dental treatment could be achieved. Among 826 patients, 235 were chosen to be treated under $\mathrm{N}_{2} \mathrm{O}$ based on their child personality characteristics. Child personality characteristics play roles in the lack of cooperation observed in many pediatric patients. Previous studies have found that temperament is correlated with dental fear and with attitudes toward dental treatment $[7,8]$.

In a Swedish sample of 124 children, shyness and negative emotionality were scored higher among children with dental fear compared to those without such fear [8]. Liga Kronina et al. found children's personalities \& behavior factors play a big impact on the various child dental anxiety (CDA) [15]. Attention problems have been associated with refusal of dental treatment [9]. However, because the dental situation always requires patience and child cooperation, personality characteristics were given remarkable consideration in deciding whether to use $\mathrm{N}_{2} \mathrm{O}$ sedation in this study. Temper tantrums, shyness, defiant, high strung, spoiled, compulsive, suspicious, fearful, tense, active and hyperactive are examples of child personality traits that have been associated with anxiety in children at their first dental visits. The results showed that a high positive response rate (86\%) was achieved using $\mathrm{N}_{2} \mathrm{O}$ sedation. In addition, the group of children with bad experiences (184 patients) was previously treated at other clinics that did not consider using $\mathrm{N}_{2} \mathrm{O}$ because the clinician did not consider child personality. Skillful dentists who have mastered BG techniques should always consider a child's personality. Many dentists overlook this point and proceed to tell, show, and perform techniques and then continue treatment, which more often ends in the child failing to respond positively. In this study, children with bad experiences were successfully treated with a positive attitude, behavior management guidance and $\mathrm{N}_{2} \mathrm{O}$ (91\%). After evaluating the patients, the behavioral rating scale was modified for each patient. While the evaluation focused mainly on the patient's medical-dental history and description of the child's personality, the rating scale provided ideas or knowledge to the dentist regarding the level of child cooperation during treatment. The PDCC study made some modifications of the Frankel's behavioral rating scale and combined it with the McDonald's classification of children's cooperative behavior. Cooperative (++) described children who showed good rapport and interest in dental procedures and who laughed and enjoyed themselves. Potentially 
Cooperative ( + ) indicated children who accepted treatment but showed cautiousness or reserved and minimal apprehension but followed the dentist's directions.

The opposite of cooperative was Uncooperative (-). These children were reluctant and uncooperative, with limited negativity, sullenness, and withdrawal. Definitely Uncooperative (--) children were those who refused treatment, cried forcefully, and who were fearful and showed extreme negativity. Potentially Cooperative children were chosen to be treated under $\mathrm{N}_{2} \mathrm{O}$ sedation because they tended to be uncooperative due to the presence of minimal apprehension, and they presented personality characteristics that were used as an additional basis. These patients had the highest rate of positive response, as shown by the results (93\%), because they were prepared and approached correctly at their first visits. Patients who were Uncooperative consisted mostly of those who had negative dental experiences, as well as personality problems, but these children were still able to have a high response rate because their fears and anxieties were reversed in a positive manner (90\%). Those children who were Definitely Uncooperative consisted mostly of young and special needs children. Some of these children responded positively, while others remained negative. Intelligence can be expected to significantly impact a child's understanding of causes, consequences, information and instructions. It can also influence their ability to communicate feelings or distress and to behave adequately in dental situations. In 1973, Rud and Kisling, concluded that children with low IQs $(<68)$ required a significantly longer time $(25-30 \%$ more) to accept dental treatment situations, [18] which explains the slightly high percentage of negative response to this group of patients (32\%) in this study, but a high rate (68\%) still responded positively. As mentioned in the introduction, the most important goals to achieve in treating pediatric patients are to encourage the child to return to the clinic for subsequent visits and to complete all dental procedures. This study showed a high rate of complete status among the patients (89\%), while those patients who were not able to complete dental treatment were classified as having incomplete status (during the time the study was being conducted) for various reasons. As per the follow-up system at the PDCC, financial inability of the patients to pay was the most common obstacle, while some cases of incomplete status were caused by the great distance of the clinic from their residences. Therefore, if the treating dentist is well skilled in managing pediatric patients from the first visit, and he or she knows how to apply behavior management combined with $\mathrm{N}_{2} \mathrm{O}$ sedation, success in completing all dental procedures with good quality of dental work will be achieved. After the completing all dental procedures, the importance of follow-up visits to maintain good oral health status was well explained to the parents.

Patients of various ages have different responses to $\mathrm{N}_{2} \mathrm{O}$ sedation. As a child grows older, his or her developmental maturity and understanding become greater. $\mathrm{N}_{2} \mathrm{O}$ is a type of BBG method that will not work alone because many pediatric patients will not immediately accept the placement of the nasal hood or mask. It requires much reassurance, with the following steps for all patients:

a) The child should feel the air coming from the mask.

b) The clinician should try it on him- or herself.

c) A picture should be shown of a child laughing with nasal hood ("Mickey Mouse nose") as a model; and

d) Distractions should be used, such as playing music.

Aitken et al. [7] observed that patients had an overwhelmingly positive response to music and would choose to listen to it at subsequent visits. To gain cooperation, the dentist should communicate with the child and recommend psychometric assessment of the child's personality to the parents. In contrast to the study conducted by Bryan, [19] our study showed that children 3 and 4 years old had high rates of positive response at $74 \%$ and 91\%, respectively. Children 4, 5 and 6 years old (91\%, 88\%, 95\%, respectively) constituted the group with the highest response rate. Good communication will establish rapport between the child and dentist that can influence cooperation. Children who were 2 years old and those with special needs showed low positive response rates (57\%, and $64 \%$, respectively) because of their limited communication abilities and the inability to follow multistep instructions. Furthermore, of the children aged 7 years old and those older than 8 years old who were treated under $\mathrm{N}_{2} \mathrm{O}$ sedation, the majority exhibited poor cooperation because of previous negative experiences, and they responded positively. It was evident that older children had higher levels of understanding compared to younger children; therefore, their levels of cooperation were high: $95 \%$ and $86 \%$, respectively (Table 5). There was no significant difference between the two sexes in their positive responses to $\mathrm{N}_{2} \mathrm{O}$. Girls showed a slightly higher positive response rate (54\%) than boys (46\%). Of the 117 patients who responded negatively under $\mathrm{N}_{2} \mathrm{O}, 72(62 \%)$ were still able to control their behaviors and reach complete case status. Of these 72 patients, only 28 treatments were completed under nasal sedation, as well as 1 with oral sedation and 2 under GA. Of the remaining 41 patients, 12 were recommended for conscious sedation or GA, but they did not return for treatment. The 33 negative response patients came for 1 or 2 visits but did not continue because of financial difficulties or lack of interest, or they wanted to wait until the child grew older and was better able to cooperate and respond better under $\mathrm{N}_{2} \mathrm{O}$.

Of the 709 patients (Table 7) who responded positively under $\mathrm{N}_{2} \mathrm{O}$ sedation, voice control was applied in 33, the HOME technique was used in 7 , and the other 105 children of young age (3 years old and younger) were treated with a PB. The parents had no objections upon explanation of the details of the necessity to apply this type of behavior management, and verbal consent was obtained. The patients' socioeconomic statuses might hinder acceptance of this 
treatment type, but it is well accepted in Saudi Arabia. Two previous studies examined specific populations (Hispanic 18 and Saudi 16) that possessed cultural norms that influenced their acceptance of behavior management techniques; thus, comparison to Western culture society is difficult. Lawrence et al. [20] found that parents rated behavior management techniques as more acceptable if the technique's purpose was more extensively explained to them. In this study, simultaneous explanation was important in alleviating parental and child anxiety. Using multiple behavior management techniques that combine science and art, including the skills of the dentist, successful treatment can be achieved. The use of $\mathrm{N}_{2} \mathrm{O}$ is a strong adjunct to behavior management for children ages 3 years of age and older. Moreover, our first goal was to prepare the children and parents psychologically by allowing them to feel comfortable at the first visit and to anticipate upcoming scenarios at the second visit. Dental fear and repeated unpleasant experiences during dental care are the most important factors leading to the use of conscious sedation and general anesthesia [21]. In our study, we were able to minimize that factor to a low percentage (4\%). Morbidity associated with inhalation sedation (IHS) is minor and infrequent, and user satisfaction is high or higher that of dental general anesthesia (DGA). In dental teaching hospitals, staffing costs for IHS are estimated to be approximately one third lower compared with outpatient DGA [22]. The general anesthetic experience was troubling in a variety of manners for both parents and children, and some parents experienced anxiety during GA [23]. Furthermore, the use of conscious sedation is stressful for the dentist, as well as for parents. It places the child at increased risk from sedative medication. Respiratory depression is highly possible if the child enters deep sedation [24,25].

\section{Conclusions}

Based on the study results, the following conclusions were made.

a) During the first visit, the clinician should pay evaluate and consider the psychometric assessment of the personality of the parents and child to psychologically prepare them to accept and understand the science and art of behavior management.

b) Clinicians should apply behavior management science stepby-step to gain the child's cooperation, which can lead to successful dental treatment.

c) $\mathrm{N}_{2} \mathrm{O}$ sedation is an effective adjunct to behavior management and works in all age groups when the clinician has the ability and knowledge to combine it with behavior management.

d) Based on this study, children with moderate to severe anxiety can be managed with proper application of behavior management and with the use of $\mathrm{N}_{2} \mathrm{O}$ sedation (with a high success rate of $91 \%$ ). e) The personality or charisma of a clinician is a natural characteristic that comes with the person. It plays a role, but the dentist's skills in performing behavior management is the most important factor and plays the most important role in treating pediatric patients and in providing good quality dental treatment.

\section{Acknowledgments}

The author would like to thank her husband, Dr. Abed Al Shammari, a former assistant professor at King Saud University, for his full support with this study and Sheiril Solomon Sanchez, the Chief of Dental Assistants at the Pediatric Dental Consulting Center, as well as the staff who contributed and assisted with the study.

\section{References}

1. (2009) American Academy of Pediatric Dentistry (AAPD). Guideline on Behavior Guidance for the Pediatric Dental Patient. Chicago, IL, USA.

2. Milgrom P, Weinstein P (1999) Early Childhood Caries A Team Approach to Prevention and Treatment. Seattle, WA, Continuing Dental Education, University of Washington in Seattle, USA p. 21.

3. Hosey MT (2002) Managing anxious children: the use of conscious sedation in Pediatric dentistry. Int J Pediatric Dent 12: 359-372.

4. (2007) American Academy of Pediatric Dentistry Council on Clinical Affairs. Guidelines on Appropriate Use of Nitrous Oxide for Pediatric Dental patients. Pediatric Dent 29: 131-151.

5. Klein U, Bucklin BA, Poulton TJ, Bozinov D (2004) Nitrous oxide concentrations in the posterior nasopharynx during administration by nasal mask. Pediatric Dent 26: 410-416.

6. Aitken JC, Wilson S, Coury D, Moursi AM (2002) The effect of music distraction on pain, anxiety and behavior in pediatric dental patients. Pediatric Dent 24: 114-118.

7. Liddel A (1990) Personality characteristics versus medical and dental experiences of dentally anxious children. J Behav Med 13(2): 183-194.

8. Klingberg G, Broberg AG (1998) Temperament and child dental fear. Pediatric Dent 20(4): 237-243.

9. Alwin NP, Murray JJ, Britton PG (1991) An assessment of dental anxiety in children. Br Dent J 171(7): 201-207.

10. Klingberg G (1995) Dental fear and behavior management problems in children: a study of measurement, prevalence, concomitant factors, and clinical effects (Thesis) Göteberg University, Göteberg, Sweden 103: 1-78.

11. White JM (2000) State of the science of music interventions. Critical care and perioperative practice. Crit Care Nurs Clin North Am 12(2): 219225.

12. Seyrek SK, Corah NL, Pace LF (1984) Comparison of three distraction techniques in reducing stress in dental patients. J Am Dent Assoc 108(3): 327-329.

13. Bajric E, Kobaslija S, Huseinbegovic A, Markovic N, Selimovic Dragas M, et al. (2016) Factors that Determine Child Behavior during Dental Treatment. Balk J Dent Med 20(2): 69-77.

14. Pinkham JR (1995) Personality Development. Managing behavior of the cooperative preschool child. Dent Clin North Am 39(4): 771-787.

15. Liga Kronina, Malgozata Rascevska, Ruta Care (2017) Psychosocial factors correlated with children's dental anxiety. Stomatologija, Baltic Dental and Maxillofacial Journal 19(3): 84-90. 
16. Kupietzky A, Ram D (2005) Effects of a positive verbal presentation on parental acceptance of passive medical stabilization for the dental treatment of young children. Pediatric Dent 27(5): 380-384.

17. Abushal MS, Adenubi JO (2003) Attitudes of Saudi parents toward behavior management techniques in pediatric dentistry. J Dent Child (Chic.) 70(2): 104-110.

18. Rud B, Kisling E (1973) The influence of mental development on children's acceptance of dental treatment. Scand J Dent Res 81(5): 343352.

19. Bryan RA (2002) The success of inhalation sedation for comprehensive dental care within the community dental service. Int J Pediatric Dent 12(6): 410-414.

20. Lawrence SM, McTigue DJ, Wilson SW, Odom JG, Waggoner WF, et al (1991) Parental attitudes toward behavior management techniques used in pediatric dentistry. Pediatric Dent 13(3): 151-155.
21. Savanheimo N, Vehkalahti MM, Pihakari A, Numminen M (2005) Reasons for and parental satisfaction with children's dental care under general anaesthesia. Int J Pediatric Dent 15(6): 448-454.

22. Lyratzopoulos G, Blain KM (2003) Inhalation sedation with nitrous oxide as an alternative to dental general anaesthesia for children. J Public Health Med 25(4): 303-312.

23. Amin MS, Harrison RL, Weinstein P (2006) A qualitative look at parents experience of their child's dental general anaesthesia. Int J Pediatric Dent 16(5): 309-319.

24. Scott S, Garcia-Godoy F (1998) Attitudes of Hispanic parents toward behavior management techniques. ASDC J Dent Child 65(2): 128-131.

25. Al Daghamin S, Balharith M, Alhazmi S, AlObaidi F, Kakti A (2017) Behavior Management Techniques in Pediatric Dentistry: How well are they accepted? Acad J Ped Neonatol 5(3): 61-65.

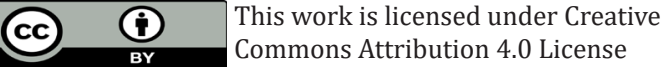

To Submit Your Article Click Here:

Submit Article

DOI: $10.32474 /$ IPDOAJ.2020.04.000186

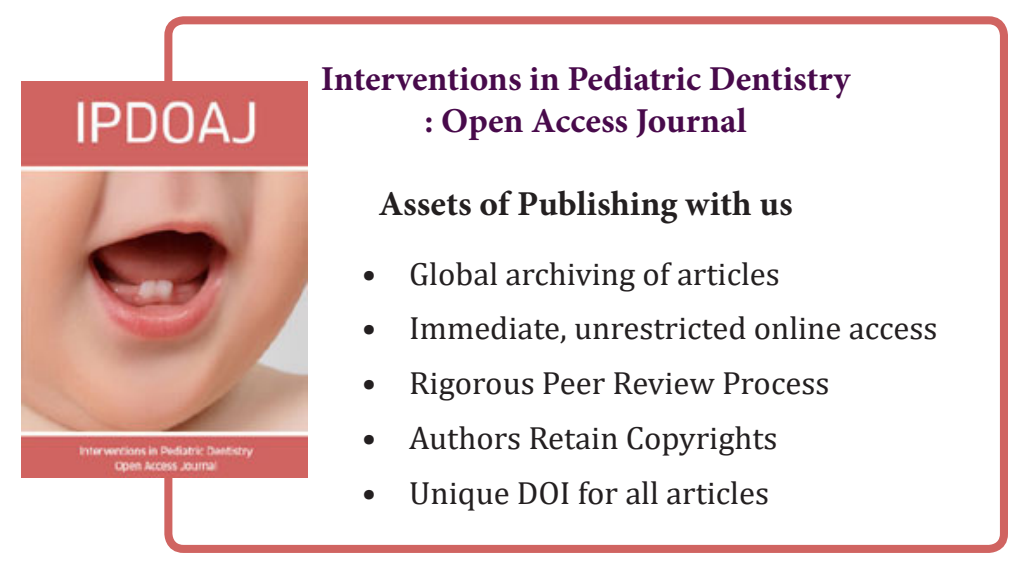

